\title{
O EXAME DE SUFICIÊNCIA EM CONTABILIDADE: UMA AVALIAÇÃO SOB A PERSPECTIVA DOS PESQUISADORES
}

THE PROFICIENCY EXAMS IN ACCOUNTING: AN ASSESSMENT FROM THE PERSPECTIVE OF RESEARCHERS

\section{EL EXAMEN DE SUFICIENCIA EN CONTABILIDAD: UNA EVALUACIÓN DESDE LA PERSPECTIVA DE LOS INVESTIGADORES}

Autores

Claudio de Souza Miranda

Doutor em Controladoria e Contabilidade (USP) - Professor Doutor da Universidade de São Paulo (USP-RP). Endereço: FEA - Av. dos Bandeirantes, 3900 - CEP 14.000-000 - Ribeirão Preto/SP, Brasil. Telefone: (16) 36023920. Identificadores (ID):

Google Citations:https://scholar.google.com.br/citations?user=JZg-dYQAAAAJ\&hl=pt-BR ORCID: http://www.orcid.org/0000-0001-7511-1416 Research Gate: https://www.researchgate.net/profile/Claudio_Miranda3 Lattes: http://lattes.cnpq.br/2122102098432475 E-mail:csmiranda@fearp.usp.br

Adriana Maria Procópio Araújo

Pós-Doutorado pela University of Illinois at Urbana-Champaign. Pós-Doutorado Universidade Federal de São Carlos (UFSCar), área de Educação. Livre-Docente e Doutora em Controladoria e Contabilidade (USP). Professora Associada da Universidade de São Paulo (USP-RP). Endereço: FEA - Av. dos Bandeirantes, 3900 - Sala 4 Bloco C - CEP 14.040-900 - Ribeirão Preto/SP, Brasil. Telefone: (16) 36023920. Identificadores (ID):

Research Gate: https://www.researchgate.net/profile/Adriana_Procopio_De_Araujo; ORCID: http://orcid.org/0000-0001-6203-3244; Google Citations: https://scholar.google.com.br/citations?user=NsC26FYAAAAJ\&hl=pt-BR Lattes: http://lattes.cnpq.br/3907440088436844 E-mail: amprocop@usp.br

Raissa Alvares de Matos Miranda Doutoranda em Administração das Organizações (USP) - Professora da Universidade Paulista (UNIP). Telefone: (16) 36023920. Identificadores (ID): Lattes: http://lattes.cnpq.br/9879264046655197

E-mail: raissamiranda@gmail.com 


\title{
RESUMO
}

Com o crescimento do ensino superior no Brasil, observa-se que o seu processo de avaliação foi ampliado com ações públicas como o Exame Nacional de Desempenho de Estudantes (ENADE), e de órgãos de classe profissional. O objetivo da pesquisa foi identificar a percepção de docentes e profissionais sobre o exame de suficiência para a profissão contábil, bem como avaliar seu atual modelo. O estudo foi descritivo e a coleta de dados foi desenvolvida por meio de uma websurvey com 1.185 autores de artigos apresentados em congressos e periódicos da área contábil. A amostra foi composta de $41,5 \%$ de pesquisadores que atuam como docentes, $29,1 \%$ atuam apenas como profissionais de mercado e $29,4 \%$ atuam nas duas áreas. Como resultado, a pesquisa apontou uma taxa de concordância de $90 \%$ com a exigência da prova, porém $57,7 \%$ entendem que a prova deveria ter revalidações periódicas, e $84,6 \%$ entendem que além do exame os profissionais deveriam comprovar atualização continuada. Com relação ao modelo que a prova é aplicada, $53 \%$ dos entrevistados concordam que é adequado. De maneira geral as questões aplicadas no exame foram consideradas medianas, mas cerca de $70 \%$ dos docentes costumam utilizá-las em maior ou menor grau em suas atividades didáticas. Os docentes entendem que bons resultados nestes exames têm importâncias para a imagem das Instituições de Ensino Superior.

Palavras-chave: Exame de suficiência. Educação superior. Ciências contábeis.

\begin{abstract}
With the growth of higher education in Brazil, it is observed that the evaluation process was extended from public actions like the national examination performance of students (ENADE), as well as professional bodies. The objective of the research was to evaluate the perception of teachers and professionals about of the sufficiency test for the accounting profession, as well as evaluate their current model. The study was descriptive and data collection was developed through a web survey with 1,185 authors of papers presented at conferences and journals in accounting. The sample was composed of $41.5 \%$ of researchers who work as teachers, $29.1 \%$ Act only as market professionals and $29.4 \%$ are operating in two areas. As a result, the survey pointed to a rate of $90 \%$ concordance with the requirement of proof, but $57.7 \%$ consider that the evidence should have re-validated, and $84.6 \%$ understand that beyond the professional examination should prove continuous update. With respect to the model that the test is applied, $53 \%$ of respondents agree that it is appropriate. In general the issues applied in the examination were considered medians, but about $70 \%$ of teachers tend to use them to a greater or lesser degree in their educational activities. Teachers understand that good results in these examinations have importance to the image of higher educational institutions.
\end{abstract}

Keywords: Examination of sufficiency. Higher education. Accounting

\section{RESUMEN}

Con el crecimiento de la educación superior en Brasil, se observa que el proceso de evaluación se amplió de acciones públicas, como el Examen Nacional de desempeño de los estudiantes (ENADE), así como los organismos profesionales. El objetivo de la investigación fue evaluar la percepción de los profesores y los profesionales sobre del examen de suficiencia para la profesión contable y para evaluar su modelo actual. El estudio fue descriptivo y la recolección de datos se desarrolla a través de una encuesta web con 1.185 
autores de los trabajos presentados en congresos y revistas de la contabilidad. La muestra se compone de $41,5 \%$ de los investigadores que actúan como maestros, el $29,1 \%$ sólo actúan como profesionales del mercado y el $29,4 \%$ trabaja en ambas áreas. Como resultado, el estudio indicó un porcentaje del $90 \%$ de concordancia con la exigencia de la prueba, pero el $57,7 \%$ cree que las pruebas deben tener revalidación periódica, y $84,6 \%$ cree que, además de examinar los practicantes deben demostrar actualización continua. Con respecto al modelo que se aplica la prueba, el 53\% de los encuestados están de acuerdo en que es apropiado. En general las preguntas aplicadas en el examen fueron consideradas medianas, pero alrededor del $70 \%$ de los maestros los usa en mayor o menor grado en actividades de aprendizaje. Los maestros entienden que los buenos resultados en estos exámenes tienen importancia para la imagen de las instituciones de educación.

Palabras-clave: Examen de suficiencia. Educación superior. Contabilidad.

\section{INTRODUÇÃO}

O processo de avaliação do ensino superior vem se expandindo e não se detém apenas na avaliação do sistema público, como o Exame Nacional de Desempenho de Estudantes (ENADE) organizado pelo Ministério da Educação (MEC). A avaliação tem sido feita também pelos órgãos de classe, como é o caso dos profissionais da contabilidade e das ciências jurídicas.

Rothen e Barreyro (2010) em revisão sobre os sistemas de avaliação da educação superior no Brasil demonstram que a partir da década de 1980 diversos sistemas de avaliação passaram a ser desenvolvidos, principalmente no sistema público de ensino superior. Os autores apontam ainda que, com a implantação da reforma da educação superior promovida pelo então Presidente Fernando Henrique Cardoso e com a implantação da Lei de Diretrizes e Bases da Educação (LDB) observou-se um expressivo crescimento do Ensino Superior no Brasil, principalmente no setor privado.

Seguindo este crescimento, houve a expansão dos sistemas de avaliação do Ensino Superior e segundo Verhine, Dantas e Soares (2006), isto se inicia em 1995 com a implantação: (i) do Exame Nacional de Curso (ENC), popularmente conhecido como "Provão"; (ii) pela implantação do Censo da Educação Superior e, (iii) utilização do sistema de Avaliação das Condições de Ensino (ACE).

O modelo do ENC foi alterado em 2003 pelo Sistema Nacional de Avaliação da Educação Superior (SINAES) e neste novo sistema incluía uma diferente abordagem para o exame de cursos denominado Exame Nacional de Desempenho dos Estudantes (ENADE), válido até os dias de hoje.

Rothen e Barreyro (2010) indicam que os diversos indicadores do SINAES foram constituídos como o "Conceito Preliminar de Cursos" e o "Índice Geral de Cursos". Estes índices subsidiam processos de supervisão do sistema de ensino.

Além dos sistemas formais de avaliação do ensino superior, desenvolvido pelo Estado brasileiro, alguns conselhos profissionais apresentam também sistemas de avaliação da formação dos alunos graduados, afim de que os mesmos possam atuar em sua área de formação, como já é feito por muitos anos na área das Ciências Jurídicas e mais recentemente para a área de Ciências Contábeis, por meio de exames de suficiência.

Segundo o Conselho Federal de Contabilidade (CFC), o Exame de Suficiência (ES) é uma prova de qualificação destinada a avaliar os conhecimentos técnicos dos Contabilistas que pretendam exercer a profissão. Entretanto, não é um exame de competência, pois busca 
assegurar que todos os neles aprovados disponham dos conhecimentos e habilidades que o diploma que receberam pressupõe.

O exame do CFC pode ser avaliado em dois períodos: o primeiro de 2000 a 2004 quando foi suspenso por não estar devidamente previsto em Lei e, o segundo, a partir de 2011 já de forma regulamentada. Alguns estudos indicam que o exame não é uma unanimidade entre os profissionais e pouco se sabe sobre a percepção da qualidade do exame.

Broietti (2014) em revisão sobre os estudos relacionados ao exame de suficiência demonstra que o tema ainda é pouco explorado pelos pesquisadores, tendo em visto que no período entre 1998 e 2013, foram encontrados quinze trabalhos nesta abordagem. Cabe ressaltar que nem todos eram análises diretas sobre o tema, mas em algum momento do trabalho o assunto foi abordado. Observa-se ainda que a maior parte dos trabalhos localizados se originam principalmente em congressos.

Assim, a questão de pesquisa para este estudo está organizada da seguinte forma: Qual a avaliação dos pesquisadores da área contábil sobre o exame de suficiência e o seu modelo de aplicação?

Diante de tais considerações, este trabalho tem como objetivo avaliar a percepção de pesquisadores (docentes e profissionais) sobre o exame de suficiência para a profissão contábil, bem como medir a percepção sobre o atual modelo de avaliação e possíveis alternativas para o mesmo.

O estudo é relevante pois levanta e analisa dados coletados diretamente com os profissionais da área e traz a tona a discussão de melhoria do processo de profissionalização da classe contábil, sendo esta sua principal contribuição.

O texto está organizado por esta introdução, na sequencia o referencial teórico acerca do assunto, seguido dos principais estudos já realizados sobre o tema. Posteriormente a metodologia da pesquisa e a análise de dados, finalizando com as principais conclusões do estudo.

\section{REFERENCIAL TEÓRICO}

A apresentação deste tópico será pela forma de explicações do surgimento do exame de suficiência no Brasil, assim como comparações com área das ciências jurídicas e com a realidade norte-americana. O estudo é descritivo e para tanto, a ênfase do estudo será na análise dos dados coletados da pesquisa.

\subsection{HISTÓRICO DO EXAME DE SUFICIÊNCIA EM CONTABILIDADE NO BRASIL \\ O exame de suficiência foi criado em 1999, por meio da Resolução CFC n. ${ }^{\circ} 853 / 99$, e} teve sua primeira prova em 2000. Diversos são os fatores e variáveis que levaram ao seu desenvolvimento, alguns dos argumentos listados pelo CFC (2007), entre eles: (i) a análise e a discussão da implantação do Exame de Suficiência durante anos nos eventos de contabilistas e de Contabilidade como uma necessidade decorrente do interesse da classe de resguardar a qualidade dos serviços prestados aos seus usuários e, (ii) o exame de suficiência como requisito para obtenção de Registro Profissional em CRC se reveste da função de fiscalização do exercício profissional, em caráter preventivo.

Moraes (2005) indica que a preocupação para implantação do exame transcendia a aspectos de conhecimento locais da contabilidade e que o CFC não tardou em alinhar-se com as demandas internacionais, que se preocupavam com a formação mundial do profissional contábil.

Revista Ambiente Contábil - ISSN 2176-9036 - UFRN - Natal-RN. v. 9. n. 2, p. 158 - 178, jul./dez. 2017. 
De acordo com o Art. $2^{\circ}$ a Resolução CFC N 853/99, o exame de suficiência seria uma prova de equalização destinada a comprovar a obtenção de conhecimentos médio, consoante aos conteúdos programáticos desenvolvidos no curso de Bacharelado em Ciências Contábeis e no Curso Técnico em Contabilidade. O exame com 50 questões de múltipla escolha foi aplicado duas vezes ao ano no período de 2000 a 2004, e o candidato só poderia obter o registro com o acerto de pelo menos $50 \%$ das questões.

Moraes (2005) afirma que a resolução que criou o exame indicava que, o mesmo seria destinado a comprovar a obtenção de conhecimentos médios, em consonância com os conteúdos programáticos desenvolvidos no curso de bacharelado em Ciências Contábeis. Entretanto, não deixava claro que conhecimentos médios seriam esses.

O relatório dos resultados do exame entre 2000 e 2004 apresentados pelo CFC (2007) indica que em alguns momentos o índice de aprovação foi baixo. Em função disso, muitos bacharéis não conseguiram seu registro, e, portanto, começaram a ingressar com ações judiciais para garantir o direito de obtenção do seu registro. Justamente pelo fato de que o mesmo ainda não estava devidamente regulamentado em forma de Lei, o que deixou margem para discussões jurídicas quanto a efetiva legalidade.

O principal argumento utilizado nas ações era de que o exame foi instituído por uma resolução do CFC. Sendo a Resolução um ato administrativo normativo inferior à Lei, o CFC não poderia utilizá-la para a imposição do registro. A principal figura jurídica que a resolução infringia era a constituição que em seu art. 5o, XIII: diz "é livre o exercício de qualquer trabalho, ofício ou profissão, atendidas as qualificações profissionais que a lei estabelecer".

O Exame de suficiência acabou por ser suspenso em abril de 2005, e a partir de então do CFC passou a trabalhar para que o exame passasse a ser tornar uma Lei. Este processo se consolidou em junho de 2010 com a promulgação da lei 12.249/10:

Os profissionais a que se refere este Decreto-Lei somente poderão exercer a profissão após a regular conclusão do curso de Bacharelado em Ciências Contábeis, reconhecido pelo Ministério da Educação, aprovação em Exame de Suficiência e registro no Conselho Regional de Contabilidade a que estiverem sujeitos. (Lei 12.249/10, Art.12).

Dessa forma, a partir de 2011 o CFC retoma a aplicação da prova para o provimento do registro profissional, com os mesmos moldes da prova interrompida em 2004.

Nogueira, Nogueira e Almeida (2013) enfatizam que o exame de suficiência é único no Brasil, ou seja, seu conteúdo é uniforme e não abrange regionalismos e aborda assuntos das seguintes áreas de conhecimentos: Contabilidade Geral, de Custo, Aplicada ao Setor Público e Gerencial, Controladoria, Teoria da Contabilidade, Legislação e Ética Profissional, Princípios de Contabilidade e Normas Brasileiras de Contabilidade, Auditoria Contábil, Perícia Contábil, Noções de Direito, Matemática Financeira, Estatística e Língua Portuguesa.

O levantamento efetuado por Eckert (2013) com as provas de 2011 e 2012, demonstra que três conteúdos em média concentram $50 \%$ das questões, sendo respectivamente Contabilidade Geral (23,5\%), Contabilidade de Custos (16\%) e Teoria da Contabilidade $(10,5 \%)$

O estudo desenvolvido por Pinheiro et al (2013) avaliaram as questões do exame de suficiência e do ENADE em função das habilidades cognitivas que a prova exigia dos candidatos. Os dados encontrados, a partir da análise pela Taxonomia de Bloom, demonstram que principalmente a prova do exame de suficiência, não exige de forma preponderante, questões que requeiram dos avaliados conhecimentos classificados como de domínio cognitivo superior. Os autores indicam que se torna fundamental que os exames busquem explorar questões que despertem para a análise, o senso crítico e a criatividade dos avaliados de forma a contribuir para uma formação focada em gestão e tomada de decisões, e não limitada ao uso de técnicas contábeis. 
Diehl e Souza (2007) destacam que outras formas de certificação profissional obrigatória também são encontradas para algumas atividades profissionais direta ou indiretamente relacionadas à contabilidade, entre elas a Certificação de Profissionais do Mercado Financeiro, instituída pelo conselho monetário nacional; e a Certificação de Auditores Independentes instituída também pelo CFC para exercício da atuação profissional do auditor.

\subsection{O MODELO NORTE-AMERICANO}

O melhor exemplo internacional de certificação para atuação na área de contabilidade é o exame do Certified Public Accountant (CPA). O modelo norte americano de educação superior em contabilidade tem algumas diferenças em relação ao modelo brasileiro, tanto que em muitos estados daquele país, para ser apto a realizar o exame do CPA, basta comprovar a aprovação em 150 horas de conteúdos contábeis na Universidade.

Segundo Moraes (2005) na época, a prova era computadorizada e com duração de 14 horas divididas nos seguintes conteúdos: prática contábil, contabilidade financeira, regulamento profissional e ambiente e conceito de negócios. Dentro dos quatro grupos de conteúdos, a composição da prova contemplava por 325 testes de múltipla escolha, 20 estudos de caso condensados, conhecidos como simulações baseadas em tarefas e por três tarefas de comunicação escrita.

Marion (1992) indicou em 1992 que o índice de aprovação no exame normalmente é baixo, visto que em média $10 \%$ daqueles que faziam a prova pela primeira vez passavam no teste, na época da publicação de seu trabalho.

Terres (2011) ressaltou ainda que depois de ser aprovado no exame e obter o CPA, o contador é era obrigado a renovar sua licença a cada dois anos tendo de comprovar participação de no mínimo 80 horas de atualização profissional em conteúdos contábeis.

Segundo Moraes (2005) apesar do longo tempo de uso do exame de CPA, há diversas críticas ao modelo, entre elas o fato de que o mesmo não busca avaliar o graduando pelo seu todo, em termo de competência e habilidades, mas sim verificar se o mesmo consegue aplicar de forma literal e condicionada as normas contábeis.

\subsection{EXAMES DE SUFICIÊNCIA NA ÁREA DAS CIÊNCIAS JURÍDICAS NO BRASIL}

Os primeiros cursos de Ciências Jurídicas ou Direito no Brasil foram criados em 1827, mas a criação da Ordem dos Advogados do Brasil (OAB) deu-se apenas em 1930, com a função de regulamentar a prática da advocacia no país. Em 1963 a partir da Lei que estabeleceu o estatuto da $\mathrm{OAB}$ o exame da ordem é criado, porém no período não era obrigatório o seu desenvolvimento. Em 1971 foi feito primeiro exame na seccional de São Paulo com duas provas, uma escrita e outra oral.

De acordo com Fagundes (2009) o exame da OAB só foi regulamentado e passado a vigorar a partir do Provimento $\mathrm{n}^{\mathrm{o}} 81 / 96$, elaborado pelo Conselho Federal da OAB. No referido Provimento consta que o Exame é obrigatório aos bacharéis de Direito e que somente após a aprovação é que o bacharel será admitido no quadro de advogados. O Provimento foi criado, tendo como suporte legal a Lei 8.096 de 1994, que dispõe sobre o Estatuto da advocacia e sobre a OAB.

A partir de 1994 a prova teve duas fases: uma com questões de múltipla escolha sobre conhecimentos gerais e outra com perguntas discursivas. Na segunda fase o candidato deveria 
escolher uma de algumas áreas indicadas, e cada Estado tinha autonomia para aplicar suas provas. Em 2007 tem-se a primeira tentativa de unificação da prova para que houvesse uma unificação dos conteúdos cobrados, fato este que se concretiza apenas em 2010.

A partir deste momento houve alguns ajustes na prova em termos de quantidade de questões e conteúdos, e de maneira geral os índices de aprovação foram baixos. As estatísticas da instituição responsável pela elaboração da prova da OAB, FGV Projetos, indicam que entre 2010 e 2012, período em que se desenvolveram oito provas, foram aprovados $18,5 \%$ dos candidatos que tentam a prova pela primeira. Os dados demonstram que 2,6\% dos candidatos tentaram por oito vezes a proficiência e não conseguiram, sendo a primeira fase da prova com maior índice de reprovação.

Em função do baixo índice de aprovação sempre surgem questionamentos sobre o valor constitucional da prova, mas em 2011 o caso foi a julgamento no Supremo Tribunal Federal (STF) que por unanimidade o considerou constitucional. Porém, há no Congresso Nacional diversos Projetos de Lei (PL) que buscam acabar com a prova ou tentar ajudar aqueles que não conseguem passar na prova a obterem o direito de exercício da profissão.

Apesar dos questionamentos, observa-se que os profissionais do direito concordam com a existência da prova conforme pesquisa desenvolvida por Miranda e Valério (2012). A pesquisa desenvolvida com 1119 advogados em todo território nacional indica que 94\% dos profissionais concordam plenamente ou parcialmente com a obrigatoriedade do exame. Cabe ressaltar que $25,6 \%$ dos advogados indicam que o atual modelo da prova não é o instrumento mais apto para avaliação de um futuro membro da OAB.

Os autores demonstram que na percepção dos profisssionais da área do direito, a baixa taxa de aprovação no exame é causada principalmente pela massificação do ensino do direito (71,3\%), pela má qualidade do ensino em função de professores despreparados $(37,3 \%)$.

\subsection{ESTUDOS ANTERIORES SOBRE A ACEITAÇÃO DO EXAME DE SUFICIÊNCIA EM CONTABILIDADE}

Terres (2011) aplicou um questionário com 80 alunos do último ano do curso de Ciências Contábeis da Universidade do Vale do Itajaí e com 280 profissionais contabilistas sendo estes 196 contadores e 84 técnicos em contabilidade. A pesquisa avaliava diversos fatores relacionados ao exame, entre eles a aceitação de sua aplicação, sendo aceite médio de $82 \%$, sendo menor entre os alunos $(73 \%)$. Em relação a importância que o exame traria a valorização profissional, em média, 59\% indicaram que este traria muita valorização e em $15 \%$ entendiam que traria pouco ou nenhuma valorização, sendo que houve uma melhor percepção entre os alunos do que entre os profissionais.

O autor ainda avaliou o grau de importância que os entrevistados acreditavam que o exame traria ao estimulo a educação continuada dos profissionais, e $18 \%$ em média acreditavam que traria pouco ou nenhuma importância. Dentro desta linha avaliou-se ainda a questão de periodicidade da prova, e $49 \%$ dos entrevistados disseram que a prova deveria ser aplicada apenas para o registro profissional, em seguida $14 \%$ entenderam que deveria ser feita de 2 em 2 anos, $17 \%$ de 5 em 5 anos, $6 \%$ de 10 em 10 anos, e 14\% que nunca deveria ser aplicada.

Dambros (2006) realizou uma pesquisa com 50 profissionais contábeis da cidade de Pato Branco-PR, em um período em que o exame estava suspenso. Os dados da pesquisa indicaram que $70 \%$ deles aprovavam o exame de suficiência, $62 \%$ acreditavam que o exame aumentava a qualificação dos profissionais contábeis e $56 \%$ eram favoráveis ao retorno do exame.

Revista Ambiente Contábil - ISSN 2176-9036 - UFRN - Natal-RN. v. 9. n. 2, p. 158 - 178, jul./dez. 2017. 
Também no período em que o exame esteve suspenso, Diehl e Souza (2007) fizeram uma pesquisa com profissionais de empresas "head hunters" sobre alguns aspectos da formação do contador e sobre o exame de suficiência. A pesquisa indicou que $90,9 \%$ dos profissionais entrevistados que o exame deveria retornar, e $72,7 \%$ que poderia haver uma certificação voluntária.

O estudo de Diehl e Souza (2007) demonstrou concordância de $81,8 \%$ de que o exame era um diferencial reconhecido pelo mercado, $90,9 \%$ concordavam que ele era adequado para atestar a qualidade profissional, 54,5\% concordavam parcialmente que ele supre deficiência dos cursos regulares de graduação e pós e, $45,5 \%$ acreditavam que caso fosse restituído o exame deveria ser aperfeiçoado.

A pesquisa realizada por Nascimento e Souza (2005) com coordenadores de 16 cursos de Ciências Contábeis do estado do Paraná indicou que 75\% dos coordenadores acreditavam que os resultados do ES indicavam plenamente o nível de preparação dos egressos para o exercício da profissão contábil, 12,5\% acreditavam que sim com algumas limitações, e 12,5\% acreditavam que não demonstravam a preparação dos alunos egressos. Ainda nesta pesquisa, $50 \%$ dos coordenadores acreditavam que a taxa média de $50 \%$ de reprovação no exame dos alunos do Paraná era relacionada a problemas dos próprios alunos, $44 \%$ que seriam problemas dos alunos, e $6 \%$ acreditavam que essa taxa seria normal.

Santos et al (2012) desenvolveram pesquisa com docentes de contabilidade do Mato Grosso do Sul e demonstraram que $94,4 \%$ deles concordavam com a obrigatoriedade do ES, $91,6 \%$ concordaram que o exame serviria como instrumento de mensuração dos conhecimentos adquiridos na faculdade. Porém, 55,6\% dos docentes acreditavam que os conhecimentos adquiridos na Universidade preparariam o acadêmico para o ES. Quando questionados sobre uma comparação dos conteúdos do ES e o Enade, 25\% concordaram que eles têm conteúdos próximos.

Nogueira, Nogueira e Almeida (2013) em pesquisa efetuada com 54 alunos da uma IES do Nordeste demonstram que os mesmos têm noção clara de que o ES era importante para sua formação e empregabilidade, e que direta ou indiretamente, a sua performance dependeria dos conhecimentos adquiridos ao longo do curso.

Resultados parecidos foram encontrados por Lima et al (2012) em pesquisa com 68 alunos de outra IES do Nordeste, onde 90\% concordaram com a exigência do exame, $94 \%$ concordaram que o exame daria credibilidade a profissão, e $91 \%$ indicavam que o exame influencia a qualidade do ensino das IES.

Bugarim et al. (2014) desenvolveram uma análise sobre o índice de aprovação de 14 edições do exame de suficiência, entre os anos de 2000 e 2012, e encontraram uma taxa média nacional de $59,7 \%$, mas que teve variações de $23,8 \%$ a $83,5 \%$. Cabe ressaltar que nas duas últimas provas de 2012 a taxa de reprovação foi elevada, sendo de $67,5 \%$ na segunda prova de 2012.

Os dados analisados por Bugarim et al. (2014) demonstram ainda que a região Sul é que tem a maior taxa média de aprovação $(57,8 \%)$. O estado com maior média de aprovação foi o de Sergipe com 69,3\% e a menor média foi a do estado do Mato Grosso com 38,7\%.

Galvão (2016) desenvolveu um levantamento com 452 profissionais da área contábil para avaliar suas percepções sobre o ES. Os profissionais indicaram que o exame proporciona principalmente a valorização da profissão e a seleção de profissionais mais capacitados. Os profissionais entenderam ainda que o modelo da prova aplicada permitiu um aperfeiçoamento da educação brasileira na área contábil e que as disciplinas são bem distribuídas entre as questões.

Dados do CFC (2007) sobre os resultados das 10 primeiras edições do exame (2000 a 2004) indicam um acerto médio de $50,5 \%$ das questões da prova. Porém há diferenças do

Revista Ambiente Contábil - ISSN 2176-9036 - UFRN - Natal-RN. v. 9. n. 2, p. 158 - 178, jul./dez. 2017. 
nível de acertos em função do conteúdo, as piores taxas de acerto nos dos conteúdos específicos de contabilidade foram em Ética e Legislação Profissional com acerto médio de $32,9 \%$ e Contabilidade de Custos com 34,6\%. Os conteúdos correlatos como estatística, a taxa média de acerto é ainda menor sendo de 30,6\%. Para os conteúdos com maiores taxas de acerto foram Contabilidade Pública (57,7\%), Princípios e Normas (54,9\%) e Perícia Contábil $(50,1 \%)$.

Cabe ressaltar que os dados encontrados nacionalmente podem ter diferenças regionais em relação aos conteúdos com maior ou menor nível de conhecimento e posterior acerto. Exemplo é o estudo desenvolvido por Valnier (2012) com egressos da UNESC que fizeram provas entre 2010 e 2011 e que indicaram os conteúdos de Princípios e Normas e de Contabilidade Pública como os que tiveram maior dificuldade de resolução na prova.

Os conteúdos cobrados no exame são baseados nas normas da profissão e, portanto, deveriam refletir as necessidades de mercado. Oliveira Neto e Kurotori (2009) demonstraram em análise dos conteúdos da prova, no período de 2000 a 2004, em contraposição ao currículo mundial do curso apresentado pela Organização das Nações Unidas (ONU) e às exigências feitas por anúncios de empregos para contadores. Os autores constataram que o exame não estava em sintonia com as exigências do currículo mundial, mas estava em sintonia com os conteúdos exigidos nos anúncios de emprego analisados à época.

\section{METODOLOGIA}

O procedimento metodológico desenvolvido foi um levantamento (survey), que se caracteriza pelo questionamento direto das pessoas cujo comportamento se deseja conhecer. De acordo com Martins e Theóphilo (2007), os levantamentos são utilizados quando se deseja responder questões acerca da distribuição de uma variável ou das relações entre características de pessoas ou grupos, da maneira como ocorrem em situações naturais. A pesquisa tem caráter descritivo e a ênfase foi na análise dos dados obtidos.

Especificamente, esta pesquisa foi uma websurvey que de acordo com Umbach (2004) trata-se de levantamento efetuado via internet. Este processo facilita a obtenção de um maior número de respondentes, além de reduzir custos de pesquisas tradicionais, como: correio, papel, e telefone, bem como evita o dispêndio de tempo de resposta e no processo de tabulação, além de evitar erros de entrada de dados.

Alguns pontos negativos da websurvey também são expostos por Dillman (2000) como o fato de o respondente não ter acesso eletrônico, ou mesmo de se conseguir os endereços eletrônicos da população almejada. No caso desta pesquisa, estes aspectos foram superados pelo fato de ser um público com perfil de acesso a meios eletrônicos e, também, pelo fato de haver meios para coleta dos contatos da população estudada.

O público alvo da pesquisa foram pesquisadores e profissionais que tiveram publicações em congressos e periódicos da área contábil. Um fator de seleção foi em relação ao endereço eletrônico (e-mail) disponível no período da coleta de dados. Assim, foram selecionados quatro congressos e dezoito periódicos com qualificação Qualis. A partir disto foi efetuado um tratamento dos dados para exclusão de duplicações, que ao final totalizaram uma população de 3407 possíveis respondentes. Foram enviadas duas ondas de solicitação de respostas em dezembro de 2014. Sabe-se que tanto em periódicos como em congressos da área contábil, encontram-se submissões de indivíduos fora da área contábil. Assim no desenvolvimento do questionário, foram feitos ajustes para que as repostas fossem efetuadas em função do perfil do respondente. 


\section{DADOS DA PESQUISA}

\subsection{CARACTERIZAÇÃO DA AMOSTRA}

Obteve-se 1185 respostas, uma taxa $34,8 \%$ de respostas da base enviada. Dos respondentes $41,5 \%$ indicaram atuar apenas como docentes, $29,1 \%$ atuam apenas como profissionais de mercado e $29,4 \%$ atuam nas duas áreas. Dos respondentes $57 \%$ são do sexo masculino e $43 \%$ do sexo feminino.

Em termos de idade, a tabela 1 indica uma maior concentração na faixa de 26 a 45 anos. Avaliando-se a idade em termos de grupamentos, observa-se diferenças significativas, onde as mulheres se concentram mais na faixa de até 35 anos $(62,0 \%)$ e os homens na faixa de 26 a 45 anos $(64,9 \%)$. Em termos de atividade profissional, os que atuam apenas como profissionais de mercado tem-se que os mesmos têm maior representatividade na faixa de até 35 anos $(78,9 \%)$ e os que atuam somente como docente tem concentração maior na faixa de 26 a 45 anos $(66,6 \%)$ e neste grupo se concentram os que com mais de 55 anos.

Tabela 1 - Estatística descritiva de outras variáveis de controle

\begin{tabular}{l|c}
\hline Variáveis de controle & Frequência Percentual \\
\hline Idade - Até 25 anos & $14,2 \%$ \\
Idade - De 26 a 35 anos & $36,2 \%$ \\
Idade - De 36 a 45 anos & $28,7 \%$ \\
Idade - De 46 a 55 anos & $14,2 \%$ \\
Idade - Mais de 55 anos & $6,7 \%$ \\
\hline Região - Norte & $2,7 \%$ \\
Região - Centro-Oeste & $7,3 \%$ \\
Região - Nordeste & $21,9 \%$ \\
Região - Sudeste & $33,8 \%$ \\
Região - Sul & $34,3 \%$ \\
\hline Tempo de Docência - Até 2 anos & $16,0 \%$ \\
Tempo de Docência - De 2 anos até 5 anos & $19,2 \%$ \\
Tempo de Docência - De 5 até 10 anos & $23,0 \%$ \\
Tempo de Docência - De 10 até 15 anos & $19,0 \%$ \\
Tempo de Docência - Mais de 15 anos & $22,9 \%$ \\
\hline
\end{tabular}

Fonte: Elaborada pelos autores.

No que tange a localização dos entrevistados, só não se obteve respostas de três estados (Acre, Alagoas e Amapá), mas a maior concentração de respondentes ficou nas regiões Sudeste e Sul (tabela 1). Os estados com maior representatividade foram SC, MG e SP.

Em termos de formação, $73,8 \%$ são graduados em contabilidade, $14,3 \%$ em administração, e o restante em economia e outros. Em $72 \%$ dos pesquisados identificou-se alguma especialização, sendo que $49,1 \%$ na área de contabilidade e controladoria. Em 77,5\% indicaram ter mestrado, sendo que $47,3 \%$ em contabilidade e $18,6 \%$ em administração. Dos $34,6 \%$ que indicaram ter doutorado, $12,9 \%$ foram em contabilidade e $11,4 \%$ em administração.

Em relação à principal IES que atuam 55,8\% dos docentes indicaram atuar em uma IES pública. Os docentes de IES pública estão concentrados principalmente na região norte $(72,7 \%)$, Centro-Oeste $(77,3 \%)$ e Nordeste $(69,1 \%)$. 
Dos que se declararam docentes, $73,7 \%$ ministram disciplinas em um curso de ciências contábeis, e os que não atuam a maior parte $(19,4 \%)$ atuam no curso de administração. Para avaliar as questões do ES, questionou-se o grupo de conteúdos que o docente atuava e as mesmas estão dispostas na tabela 2. As disciplinas de administração e economia foram alocadas separadamente por não serem conteúdos abordados no exame de suficiência.

Tabela 2 - Disciplinas ministradas

\begin{tabular}{l|c}
\hline Disciplina & Percentual (\%) \\
\hline Contabilidade de custos/gerencial/controladoria & $39,5 \%$ \\
\hline Contabilidade financeira/societária & $35,1 \%$ \\
\hline Finanças & $12,5 \%$ \\
\hline Contabilidade Tributária & $10,4 \%$ \\
\hline Auditoria & $9,5 \%$ \\
\hline Contabilidade Pública & $7,7 \%$ \\
\hline Métodos quantitativos (cálculo e estatística) & $6,5 \%$ \\
\hline Perícia & $5,6 \%$ \\
\hline Direito & $0,5 \%$ \\
\hline Outras & $10,4 \%$ \\
\hline Administração & $5,8 \%$ \\
\hline Economia & $1,2 \%$ \\
\hline Fonte: Elaborada pelos autores &
\end{tabular}

Aos que indicaram serem graduados em ciências contábeis, questionou-se se os mesmos tinham o registro profissional e $77,0 \%$ indicaram ter o mesmo ativo, 10,3\% fizeram o registro, mas não está mais ativo, e 12,7\% disseram nunca ter obtido. Entre os que fizeram o registro, estando ativo ou não, $41 \%$ fizeram o ES, principalmente os mais novos até 25 anos.

\subsection{ANÁLISE DOS DADOS}

Questionou-se a todos os entrevistados sobre o seu grau de concordância sobre o ES, e os dados da tabela 3 indicam uma concordância plena e parcial de $90 \%$. Observa-se que $8,5 \%$ indicam discordância plena e parcial. Uma adaptação da escala qualitativa para quantitativa de 1 a 5 indica uma concordância média de 4,5.

Tabela 3 - Concordância com a obrigatoriedade do exame de suficiência

\begin{tabular}{l|c}
\hline Grau de concordância & Percentual (\%) \\
\hline Discordo Plenamente & $5,2 \%$ \\
\hline Discordo Parcialmente & $3,3 \%$ \\
\hline Não concordo nem discordo & $1,5 \%$ \\
\hline Concordo parcialmente & $16,0 \%$ \\
\hline Concordo plenamente & $74,0 \%$ \\
\hline Fonte: Elaborada pelos autores.
\end{tabular}

São observadas diferenças significativas de avaliação em termos de forma de atuação e formação de graduação. No quesito graduação, os formados em contabilidade têm concordância de $92,3 \%$ com a prova e $6,7 \%$ de discordância. Já entre os que tinham formação em administração e economia houve a concordância de $83,8 \%$ e a discordância de $13,8 \%$. O menor índice de aprovação ao exame foi encontrado entre os que atuam somente no mercado, tendo concordância de $87,8 \%$ e discordância de $10,4 \%$. Observa-se ainda que entre os que se formaram em contabilidade e não obtiveram o registro profissional, o nível de discordância com o exame foi de $19,8 \%$.

Revista Ambiente Contábil - ISSN 2176-9036 - UFRN - Natal-RN. v. 9. n. 2, p. 158 - 178, jul./dez. 2017. 
A revisão de literatura indicou que há alguns questionamentos sobre a necessidade de que o profissional precisaria renovar seu registro periodicamente. Questionados sobre este tópico, observa-se que pouco mais de um terço dos respondentes $(34,9 \%)$ indicaram que deveria haver uma única prova e $7,3 \%$ que não deveria haver a prova. Em $57,7 \%$ dos respondentes indicaram que deveria haver revalidação de periodicamente, principalmente a cada cinco anos, conforme demonstra a tabela 4. Os resultados encontrados indicam índice maior de aprovação, para revalidação do diploma, do que os resultados encontrados por Terres (2011). E o índice de indicação de não haver obrigatoriedade da prova é menor que os $10 \%$ encontrados na pesquisa de Galvão (2016).

Tabela 4 - Necessidade de revalidação da prova

\begin{tabular}{l|c}
\hline Alternativas & Percentual (\%) \\
\hline Uma única prova & $34,9 \%$ \\
\hline Revalidação a cada 5 anos & $43,2 \%$ \\
\hline Revalidação a cada 10 anos & $14,5 \%$ \\
\hline Não deveria ter prova & $7,3 \%$ \\
\hline Fonte: Elaborada pelos autores. &
\end{tabular}

Outra forma de revalidação do exame seria a comprovação de educação continuada, conforme já observado pelo modelo utilizado pelo CPA, que exige 80 horas a cada dois anos, e o caso do registro de auditor no Brasil. O questionamento "O CPA exige que os profissionais apresentem atualização profissional de 80 horas a cada dois anos. A pesquisa abordou a seguinte questão: Você concorda que isso deveria ocorrer também no Brasil?" e observa-se pela tabela 5 que há $84,6 \%$ de concordância plena e parcial e $10,9 \%$ de discordância. Um ajuste das notas de concordância para uma escala numérica de 1 a 5 apresenta uma nota 4,2 para o questionamento.

Tabela 5 - Necessidade de comprovação de educação continuada

\begin{tabular}{l|c}
\hline Concordância & Percentual (\%) \\
\hline Discordo Plenamente & $5,4 \%$ \\
\hline Discordo Parcialmente & $5,5 \%$ \\
\hline Não concordo nem discordo & $4,5 \%$ \\
\hline Concordo parcialmente & $36,8 \%$ \\
\hline Concordo plenamente & $47,8 \%$ \\
\hline
\end{tabular}

Fonte: Elaborada pelos autores.

Observam-se diferenças significativas de concordância entre os contadores que não fizeram o registro profissional que indicam uma taxa de discordância de 15,3\%. Há também diferenças ao se analisar o posicionamento em relação ao tempo de validade da prova, visto que as maiores taxas de discordância são encontradas entre os que indicam que não deveria haver a prova $(25,3 \%)$ e que deveria haver uma única prova $(17,2 \%)$. Já entre os que defendem a revalidação da prova, as taxas de discordância de comprovação de educação continuada, são de $6,9 \%$ para quem indica renovação a cada 10 anos, e de $4,7 \%$ para os que indicam renovação a cada cinco anos.

Buscou-se avaliar a percepção de todos os respondentes, sobre a capacidade de medir conhecimento que a prova do ES tem. O questionamento efetuado foi: "A prova do exame de suficiência contém 50 testes, e o aluno para ser aprovado precisa acertar somente metade das questões. Você acredita que este tipo de prova consegue medir o grau de aprendizado do aluno durante sua graduação, ou seja, mede a qualidade do ensino oferecido pela IES?". A tabela 6 indica uma concordância de 52,9\%, concentrada principalmente na parcial, e uma 
discordância de 40,4\%. A conversão dos dados qualitativos para uma escala de 1 a 5 apresenta uma nota 3 para este questionamento.

Tabela 6 - Concordância com o modelo da prova.

\begin{tabular}{l|c}
\hline Concordância & Percentual (\%) \\
\hline Discordo Plenamente & $16,9 \%$ \\
\hline Discordo Parcialmente & $23,5 \%$ \\
\hline Não concordo nem discordo & $6,7 \%$ \\
\hline Concordo parcialmente & $46,2 \%$ \\
\hline Concordo plenamente & $6,8 \%$ \\
\hline Fonte: Elaborada pelos autores.
\end{tabular}

Fonte: Elaborada pelos autores.

Foram encontradas diferenças significativas de avaliação em relação aos respondentes que tem o registro profissional ou não, entre os que não obtiveram o registro ou já cancelaram o mesmo, o nível de discordância quanto a capacidade de medir o nível de aprendizado é maior $45,9 \%$ e $43,4 \%$ respectivamente, contra $36,2 \%$ dos que tem o registro ativo. Ao se fazer a análise cruzada com o grau de concordância da obrigatoriedade da prova, observa-se diferenças significativas de avaliação, visto que quanto maior o grau de concordância da prova, maior é o grau de concordância de sua capacidade de medir o aprendizado do aluno. Desta forma observa-se também que há entre as duas questões uma correlação de 0,296 com significância de $99 \%$.

Como análise comparativa, na pesquisa de Galvão (2016) desenvolvida com profissionais da área contábil, 53,6\% indicaram serem favoráveis a continuidade do exame, mas acreditavam que ele deve passar por alguns ajustes. E a principal indicação foi de que houvesse uma melhor adequação das questões à realidade empresarial.

Como avaliação de outras possibilidades para o exame fez-se uma argumentação em relação a uma comparação ao exame da ordem. Primeiramente avaliou-se o nível de conhecimento dos entrevistados em relação a este exame a partir de uma escala de 1 (nenhum) a 5 (pleno). A tabela 7 indica que de maneira geral há um baixo conhecimento do exame visto que cerca de $2 / 3$ dos entrevistados deram nota 1 ou 2 para seu conhecimento da prova.

Tabela 7 - Conhecimento da prova da OAB.

\begin{tabular}{l|c}
\hline Nota & Percentual (\%) \\
\hline $1-$ Nenhum & $43,9 \%$ \\
\hline 2 & $20,0 \%$ \\
\hline 3 & $20,0 \%$ \\
\hline 4 & $11,6 \%$ \\
\hline $5-$ Pleno & $4,5 \%$ \\
\hline Média & $\mathbf{2 , 1}$ \\
\hline Fonte: Elaborada pelos autores.
\end{tabular}

Apresentou-se então uma breve descrição do modelo do exame da ordem e questionou-se: "O exame da ordem $(\mathrm{OAB})$ é organizado hoje em duas provas; a primeira prova é uma prova objetiva, com 80 questões de múltipla escolha, e a segunda é uma prova prático-profissional, que contém uma peça profissional e quatro questões discursivas. Só passa para a segunda fase quem atinge um determinado patamar de pontuação. Você acredita que este modelo poderia ser também aplicada ao exame do CRC?" Observa-se pela tabela 8 que existe um grau de concordância de $69,1 \%$. 
Tabela 8 - Concordância da aplicação do modelo da OAB para o CRC.

\begin{tabular}{l|c}
\hline Nível de concordância & Percentual (\%) \\
\hline Discordo Plenamente & $10,5 \%$ \\
\hline Discordo Parcialmente & $8,0 \%$ \\
\hline Não concordo nem discordo & $12,4 \%$ \\
\hline Concordo parcialmente & $41,6 \%$ \\
\hline Concordo plenamente & $27,5 \%$ \\
\hline Fonte: Elaborada pelos autores.
\end{tabular}

Fonte: Elaborada pelos autores.

Entre os graduados em contabilidade, observa-se maior discordância em relação ao modelo da $\mathrm{OAB}$, principalmente entre os que nunca fizeram o registro $(30,6 \%)$, valor este que representa o dobro dos que tem ou já tiveram o registro (15,3\%). O nível de concordância deste questionamento tem correlações significativas em $99 \%$ com as questões sobre a concordância com a obrigatoriedade do exame atual $(0,408)$, e com a forma de avaliação do exame atual $(0,102)$.

Entre os docentes que atuavam no curso de ciências contábeis procurou-se avaliar os conhecimentos que o mesmo tinha em relação ao ES e como sua IES atua em relação ao mesmo. Desta forma o primeiro questionamento foi sobre a percepção do docente de como os discentes da IES estariam se saindo na prova do exame. A tabela 9 indica uma percepção superior a $75 \%$ de resultados positivos dos alunos, e apenas $15 \%$ dos docentes não tem ideia de como os alunos tem se saído. O maior desconhecimento está concentradao principalmente em docentes que atuam em disciplinas complementares como administração, economia e métodos quantitativos.

Tabela 9 - Como os discentes da IES tem se saído no exame de suficiência

\begin{tabular}{l|c}
\hline Alternativas & Percentual (\%) \\
\hline Acredito que em média poucos tem passado & $7,6 \%$ \\
\hline Acredito que em média tem tido resultados positivos & $31,7 \%$ \\
\hline Acredito que a maioria tem tido resultados positivos & $45,4 \%$ \\
\hline Não tenho nenhuma informação & $15,3 \%$ \\
\hline Fonte: Elaborada pelos autores.
\end{tabular}

Foi observada diferença significativa de avaliação entre os docentes de escolas privadas e públicas, na qual se observa que os docentes de privadas tem uma percepção menor dos índices de aprovação dos alunos, e também é maior seu nível de desconhecimento dos resultados dos alunos de sua IES, sendo a mesma percepção para os docentes das regiões Norte e Centro-Oeste.

Em relação à preparação dos alunos para o Exame do CRC, questionou-se se a principal IES de atuação do docente desenvolvia atividades preparatórias. Os dados da tabela 10 demonstram que o nível de oferecimento de conteúdos preparatórios de forma contínua é de 19,4\%. Neste caso, não foram excluídas as possíveis duplicações de docentes de uma mesma IES. Ao se analisar docentes de IES públicas e privadas observam-se diferenças significativas, visto que $28,3 \%$ dos docentes de IES públicas indicaram o oferecimento às vezes ou frequentemente, contra $65,2 \%$ dos docentes de privadas. Quando a IES oferecia algum curso preparatório, $49,3 \%$ dos docentes pesquisados ministravam disciplina deste enfoque. 
Tabela 10 - IES oferece disciplinas preparatórias para o exame de suficiência

\begin{tabular}{l|r}
\hline Alternativas & \multicolumn{1}{c}{ Percentual (\%) } \\
\hline Não sei & $14,0 \%$ \\
\hline Nunca oferece & $41,4 \%$ \\
\hline Oferece às vezes & $25,2 \%$ \\
\hline Oferece frequentemente & $19,4 \%$ \\
\hline Fonte: Elaborada pelos autores.
\end{tabular}

Como base de comparação, questionou-se se as IES ofereceriam cursos preparatórios para o ENADE. Em $38,8 \%$ dos docentes indicaram que suas IES oferecem em algum momento disciplinas preparatórias para o ENADE (tabela 11). Essa indicação é novamente maior entre docentes de IES privadas $63,7 \%$ contra $19,1 \%$ de docentes de IES públicas. O cruzamento do oferecimento de cursos preparatórios, indica que quando uma IES oferece cursos preparatórios para o Exame do CRC, ela também oferece cursos para o ENADE. E quando não oferece para o exame do CRC acabam também não oferecendo para o ENADE.

Tabela 11 - IES oferece disciplinas preparatórias para o ENADE

\begin{tabular}{l|c}
\hline \multicolumn{1}{c|}{ Alternativas } & Percentual (\%) \\
\hline Não sei & $17,4 \%$ \\
\hline Nunca oferece & $43,8 \%$ \\
\hline Oferece a toda as turmas independente de terem que fazer a prova do ENADE & $16,6 \%$ \\
\hline Oferece apenas para as turmas que terão que fazer a prova do ENADE & $22,1 \%$ \\
\hline \multicolumn{2}{c}{ Fonte: Elaborada pelos autores. }
\end{tabular}

Questionou-se os docentes sobre sua concordância com estes cursos e disciplinas preparatórias, e observa-se que na média há uma concordância plena e parcial de cerca de $50 \%$ para os dois exames (tabela 12 ). Identifica-se correlação $(0,795)$ entre as respostas dos dois exames com confiança de $99 \%$, o que demonstra que os docentes têm percepções próximas aos dois exames. Observa-se ainda que os docentes de IES privadas têm maior concordância com conteúdos preparatórios, $65 \%$ em média, contra $35 \%$ em média de docentes de IES públicas.

Tabela 12 - Concordância com o oferecimento de disciplinas preparatórias

\begin{tabular}{|c|c|c|}
\hline Nível de concordância & $\mathrm{CRC}$ & ENADE \\
\hline Discordo Plenamente & $30,5 \%$ & $32,0 \%$ \\
\hline Discordo Parcialmente & $10,3 \%$ & $10,2 \%$ \\
\hline Não concordo nem discordo & $7,4 \%$ & $8,2 \%$ \\
\hline Concordo parcialmente & $27,9 \%$ & $29,9 \%$ \\
\hline Concordo plenamente & $23,7 \%$ & $19,7 \%$ \\
\hline
\end{tabular}

Fonte: Elaborada pelos autores.

Em relação ao ES e ao ENADE, questionou-se a todos os docentes pesquisados, qual a sua percepção em relação à importância dos mesmos para a imagem da IES, a partir de uma escala de 7 pontos. Os dados da tabela 13 indicam haver importância maior ao ES, mas a média geral dos dados é 4,07. Não foram encontradas diferenças significativas, mas observase entre docentes de IES Públicas uma importância um pouco maior ao ENADE. 
Tabela 13 - Importância para imagem da IES

\begin{tabular}{l|c}
\hline Escala & Percentual (\%) \\
\hline Enade - 1 & $23,6 \%$ \\
\hline 2 & $6,8 \%$ \\
\hline 3 & $4,4 \%$ \\
\hline 4 & $22,1 \%$ \\
\hline 5 & $11,5 \%$ \\
\hline 6 & $9,9 \%$ \\
\hline Exame de suficiência -7 & $21,7 \%$ \\
\hline Fonte: Elaborada pelos autores. &
\end{tabular}

Especificamente em relação ao exame do CRC, questionou-se aos docentes que atuavam no curso de contabilidade, se os mesmos costumavam olhar as questões da prova, e a tabela 14 indica que 51,2\% dos docentes indicaram uma alta frequência (4 e 5) de observação das questões. Ao se avaliar docentes de escolas públicas e privadas, observa-se diferença significativa, sendo que o maior nível foi observado entre docentes de IES privadas $(60,4 \%)$ contra $43,9 \%$ dos docentes de IES Públicas.

Tabela 14 - Frequência com que olha as provas do exame de suficiência

\begin{tabular}{l|r}
\hline Frequência & \multicolumn{1}{|c}{ Percentual (\%) } \\
\hline Nunca -1 & $16,0 \%$ \\
\hline 2 & $12,6 \%$ \\
\hline 3 & $20,2 \%$ \\
\hline 4 & $20,4 \%$ \\
\hline Sempre -5 & $30,9 \%$ \\
\hline Fon
\end{tabular}

Fonte: Elaborada pelos autores.

Fez-se uma avaliação da observação das questões em função das disciplinas lecionadas. Os dados da tabela 15 indicam que há uma maior observação entre as matérias mais específicas como a contabilidade tributária, auditoria, pública e perícia.

Tabela 15 - Frequência com que olha as provas por disciplina ministrada

\begin{tabular}{lr}
\hline \multicolumn{1}{|c|}{$\%$} & $66,7 \%$ \\
\hline Disciplinas & $63,8 \%$ \\
\hline Auditoria & $63,1 \%$ \\
\hline Contabilidade Pública & $61,7 \%$ \\
\hline Perícia & $60,3 \%$ \\
\hline Contabilidade financeira-societária & $59,0 \%$ \\
\hline Contabilidade de custos/gerencial/controladoria & $47,6 \%$ \\
\hline Finanças & $30,9 \%$ \\
\hline Métodos quantitativos (cálculo e estatística) &
\end{tabular}

Além da indagação sobre a observação das questões, questionou-se sobre o uso das mesmas em sala de aula. Os dados da tabela 16 indicam quem $72,5 \%$ dos docentes já utilizam, com maior ou menor frequência, as questões do ES em suas atividades didáticas. Novamente observa-se diferença significativa ao se analisar docentes de escolas públicas e privadas, visto que a utilização, independente da frequência, é de $81,3 \%$ para docentes de IES privadas e de $65,6 \%$ entre os docentes de IES públicas. A pesquisa de Bonifácio e Callegari (2012) desenvolvida com 42 docentes de uma IES privada de SC, indicam que os docentes de

Revista Ambiente Contábil - ISSN 2176-9036 - UFRN - Natal-RN. v. 9. n. 2, p. 158 - 178, jul./dez. 2017. 
formação básica pouco utilizam as questões do ES, e os de disciplinas de formação profissional tem uma maior utilização, mas não que seja de foram frequentes.

Tabela 16 - Uso das questões do exame em atividades de aula

\begin{tabular}{l|r}
\hline Alternativas & Percentual $(\%)$ \\
\hline Não e nunca pensei nesta possibilidade & $13,9 \%$ \\
\hline Não, mas já pensei nesta possibilidade & $13,6 \%$ \\
\hline Sim, mas uso com baixa frequência & $35,8 \%$ \\
\hline Sim uso de forma frequente & $36,7 \%$ \\
\hline
\end{tabular}

Fonte: Elaborada pelos autores.

Procurou-se avaliar a percepção dos docentes sobre o nível das questões que são oferecidas no exame do CRC. Pela tabela 17 observa-se que as questões com avaliação de dificuldade mais baixa foram as de métodos quantitativos e perícia. Em relação às questões de perícia, observa-se que as mesmas têm sido muito similares, chegando a ter repetição na integra em duas edições da prova (questão 40 da prova 2/2013 e a questão 46 da prova $1 / 2014)$.

Tabela 17 - Dificuldade das questões da prova

\begin{tabular}{l|r|r|c|c}
\hline \multicolumn{1}{c|}{ Conteúdos } & Fáceis & Medianas & Difíceis & Não sei avaliar / Nunca vi \\
\hline Métodos quantitativos & $44,7 \%$ & $50,0 \%$ & $5,3 \%$ & $30,9 \%$ \\
\hline Pericia & $43,2 \%$ & $52,3 \%$ & $4,5 \%$ & $6,4 \%$ \\
\hline Auditoria & $24,0 \%$ & $72,0 \%$ & $4,0 \%$ & $6,3 \%$ \\
\hline Contabilidade financeira-societária & $22,7 \%$ & $72,9 \%$ & $4,3 \%$ & $6,1 \%$ \\
\hline Contabilidade Pública & $22,6 \%$ & $71,0 \%$ & $6,5 \%$ & $4,6 \%$ \\
\hline Finanças & $22,5 \%$ & $67,5 \%$ & $10,0 \%$ & $23,8 \%$ \\
\hline Contabilidade Tributária & $24,7 \%$ & $63,0 \%$ & $12,3 \%$ & $6,9 \%$ \\
\hline $\begin{array}{l}\text { Contabilidade de } \\
\text { custos/gerencial/controladoria }\end{array}$ & $16,4 \%$ & $76,6 \%$ & $6,9 \%$ & $8,4 \%$ \\
\hline
\end{tabular}

Fonte: Elaborada pelos autores.

\subsection{ACHADOS DA PESQUISA}

No questionário foram abertos espaços, não obrigatórios, para comentários gerais sobre a prova e possíveis sugestões, dessa forma apresenta-se a seguir algumas declarações que reforçam os resultados encontrados. As principais colocações feitas foram para que a prova tivesse melhorias, principalmente para que tivesse questões abertas que cobrassem mais raciocínio dos alunos, além dos testes com cinco alternativas, e que a nota de corte fosse maior.

Essas indicações reforçam os achados de Pinheiro et al (2013) quando analisaram a dificuldade das questões do ES, bem como a indicação feita por profissionais de contabilidade na pesquisa de Galvão (2016) de que a prova tivesse questões que instigassem o lado crítico e argumentativo dos contadores, bem como que se acrescentassem questões dissertativas com "casos empresariais" para serem resolvidos pelos contadores. Como exemplo apresenta-se a declaração de uma docente de uma IES privada do Estado da Bahia.

Respondente a: Mesclaria questões objetivas e discursivas...é importante avaliar como aquele futuro profissional, se posiciona criticamente, articula as ideias em um texto, se o mesmo "sabe" escrever e etc ... As questões objetivas deveriam conter cinco opções de respostas e não apenas 4.

Revista Ambiente Contábil - ISSN 2176-9036 - UFRN - Natal-RN. v. 9. n. 2, p. 158 - 178, jul./dez. 2017. 
Cabe ressaltar que as colocações por maior rigidez na prova, são indicadas principalmente em função da grande expansão do ensino privado sem que haja maior controle sobre sua qualidade, como exemplo apresenta-se parte da declaração de um docente de uma IES privada do nordeste do pais.

Respondente b:... a forma descontrolada como se abre curso de ciências contábeis como se abrisse lanchonete é vergonhoso e mais vergonhoso é esses alunos quererem ser profissionais de contabilidade sem saber nada...onde está o problema? Está em tudo, no ministério da educação que perdeu a seriedade em abrir o curso e o CRC que afrouxa naquela prova de baixíssima qualidade para ingresso na profissão...virei muita noite para fazer minha graduação e mestrado e hoje vejo gente que só quer ler slides e marcar X.

Conforme exposto por Bugarim et al (2014) há um alto nível de aprovação no exame e isto também é criticado pelos docentes. Como exemplo, apresenta-se a declaração de um docente do Estado do Espírito Santo.

Respondente c: $O$ Exame não é feito para melhorar a qualidade do profissional habilitado. $O$ nível da prova é muito fácil e a pontuação mínima é ridícula. A falta de barreira de entrada prejudica a qualidade do profissional que temos no mercado e, consequentemente, a imagem do Contador no Brasil.

Além do ES observou-se que os pesquisadores indicaram a importância da comprovação da educação continuada, utilizando os modelos hoje utilizados pelo CPA, e mesmo pelo CRC para os profissionais auditores. Dentro deste enfoque pode-se observar a declaração de um docente do Paraná.

Respondente d: Considero válido, mas insuficiente para a qualidade dos profissionais. Considero que seja pertinente a qualificação continuada em todas as áreas requerida por meio de carga horárias de curso apresentada em cada periodo. Parte dos cursos poderia ser fornecido pelo sistema $C R C / C F C$.

Para esse assunto, um recente estudo aborda especificamente a importância da educação continuada para os docentes dos cursos de ciências contábeis, sugerindo que a preparação pedagógica para os futuros docentes seja incluída como disciplina obrigatória pelos programas de pós-graduação em contabilidade do Brasil (Lapini, 2012).

Apesar de não ser o foco central da pesquisa, questionou-se ainda sobre a obrigatoriedade de exames de suficiência para outras áreas profissionais. Observou-se que nas áreas da saúde a concordância plena e parcial para obrigatoriedade foi superior as $85 \% \mathrm{em}$ todas áreas indicadas, e esse índice foi observado também na engenharia. $\mathrm{Na}$ área de humanidades a concordância foi de $68 \%$ para pedagogia e $61 \%$ em média para administração e economia. Como exemplo da importância de exames para outras áreas destaca-se a colocação de um docente de uma universidade pública do Estado da Paraíba.

Respondente e: Acho importante que todas as profissões aprimorem os seus modelos de avaliar os futuros profissionais, pois a sociedade padece quando a quantidade de profissionais não acompanha na mesma proporção a qualidade desses profissionais.

Entretanto, apesar do alto grau de concordância com a prova, ainda existem docentes e profissionais que discordam de sua existência. Isto pode ser observado na declaração de um docente de uma universidade pública do Estado do Rio Grande do Norte.

Respondente f: Não entendo ser preciso passar por um exame para exercer a profissão. $O$ mercado é bastante seletivo. Aqueles alunos que apresentarem melhores competências e habilidades, certamente serão inseridos mais facilmente no campo de atuação profissional, independente do curso de formação.

Reforçar a discussão acerca do assunto é uma das principais contribuições deste estudo uma vez que, embora sejam apontamentos específicos de alguns pesquisadores, as declarações corroboram tal necessidade. 


\section{CONSIDERACOES FINAIS}

O Exame de Suficiência do CRC é uma realidade e para tanto, estudos analisando sua condição de efetividade são oportunos e trazem informações para a melhoria do processo. A pesquisa teve como foco contribuir para a discussão e levantou a questão embasada no aspecto de saber qual a avaliação dos pesquisadores da área contábil sobre o referido exame e o seu atual modelo de aplicação.

A pesquisa desenvolvida neste trabalho teve como objetivo avaliar o ES sob a ótica de pesquisadores da área contábil, sejam eles docentes e/ou profissionais, a partir de uma base mais ampla do que estudos anteriores avaliados.

Foi feita uma pesquisa descritiva com 1185 observações por meio de coleta de dados websurvey. Como principais resultados, constata-se que de maneira geral há aprovação de sua existência, mas há diversas indicações de alterações, como a possível revalidação da prova, e a necessidade de remodelação da forma como a prova é aplicada e de seus conteúdos.

Como contribuição e pesquisas futuras, os dados encontrados neste levantamento permitem que sejam feitas outras avaliações com outros públicos, entre eles o CFC e os Conselhos Regionais, para avaliar percepção dos mesmos sobre as indicações desta pesquisa. Outro público que pode ser avaliado, de forma mais ampla, seriam discentes tanto entrantes como formandos.

\section{REFERÊNCIAS}

BONIFÁCIO, R.; CALLEGARI, O.M. O exame de suficiência contábil e a percepção dos professores do curso de ciências contábeis. In: XII Colóquio Internacional sobre Gestão Universitária nas Américas. Anais ... Veracruz-México, 2012

BROIETTI, C. Exame de Suficiência do Conselho Federal de Contabilidade: Observação das Publicações Relacionadas ao Tema. In: $5^{\circ}$ Congresso UFSC de Controladoria e Finanças. Anais ... Florianópolis, 2014.

BUGARIM, M.C.C; RODRIGUES, L.L.; PINHO, J.C.C.; MACHADO, D.Q. Análise histórica dos resultados do exame de suficiência do conselho federal de contabilidade. Revista de Contabilidade e Controladoria. v.6, n.1, p. 121-136, 2014.

CONSELHO FEDERAL DE CONTABILIDADE. Caderno analítico do exame de suficiência: histórico dos resultados. Brasília: CFC, 2007.

DAMBROS, F.O. O extinto exame de suficiência. Monografia de conclusão da Especialização em Gestão Contábil e Financeira do CEFET- PR, 2006.

DIEHL, C.A; SOUZA, M.A. Formação, certificação e educação continuada: um estudo exploratório do profissional contábil sob a óptica das empresas head hunters. Revista de Administração e Contabilidade da Unisinos. v.4, n.3, 233-248, 2007.

DILLMAN, D. A. Mail and Internet surveys: The tailored design method. New York: John Wiley \& Sons, Inc, 2000. 
ECKERT, A.; MECCA, M.S.; BIASIO, R.; NEGRI, V. C. Exame de Suficiência: principais conteúdos abordados e as variáveis econômicas e sociais que podem influenciar nos índices de aprovação. In: XIV Convenção de Contabilidade do Rio Grande do Sul, Bento Gonçalves, 2013. Anais... Bento Gonçalves (RS): CRC, 2013.

FAGUNDES, R.C. Ensino jurídico e exame de ordem: história, dilemas e desafios. In: VIII Seminário Nacional de Estudos e Pesquisas, Anais ... Campinas 2009.

GALVÃO, N. Percepção dos contadores sobre o exame de suficiência do CFC. Revista Catarinense da Ciência Contábil, v. 15, n. 45, p.49-62, 2016

LAPINI, V.C. Panorama da formação do professor em Ciências Contábeis pelos cursos Stricto Sensu no Brasil. Dissertação (Mestrado em Ciências Contábeis) Programa de mestrado em Ciências Contábeis da Faculdade de Economia, Administração e Contabilidade de Ribeirão Preto da Universidade de São Paulo. Ribeirão Preto, 2012.

LiMA, C. E. S.; CAMPElO, K. S.; SILVA, A. C. B.; GONÇAlVES, V. L. Exame de suficiência: um estudo sobre a percepção de alunos concluintes de cursos de ciências contábeis do município de caruaru-pe quanto a sua preparação face ao conhecimento adquirido na graduação. In: XIX Congresso Brasileiro de Contabilidade. Anais ... Belém. 2012

MARION, J.C. Aspectos do Ensino da Contabilidade nos Estados Unidos. Caderno de Estudos n. 7 FIPECAFI, 1992.

MARTINS, G. A.; THEÓPHILO, C. R. Metodologia da investigação científica para ciências sociais aplicadas. São Paulo: Atlas, 2009.

MIRANDA, C.S.; VALÉRIO, M.A.G. Avaliação do Exame da OAB. Disponível em $<\mathrm{http} / / / \mathrm{www}$.fundace.org.br/arquivos_diversos/ftp/analise_exame_oab.pdf $>$ visualizado em abril/2015.

MORAES, E.F. O impacto das grades curriculares do curso de bacharelado em ciências contábeis no desempenho das instituições de ensino superior do estado da Paraíba no exame de suficiência no período de 2000 a 2004. Dissertação (Mestrado em Ciências Contábeis) Programa Multi-institucional e Inter regional de Pós-graduação em Ciências Contábeis da Universidade de Brasília. João Pessoa, 2005.

NASCIMENTO, C.L.; SOUZA, M.A. Os indicadores sobre a qualidade dos cursos de Ciências Contábeis: um estudo acerca dos resultados do ENC e do Exame de Suficiência. In: IX Congresso Internacional de Custos. Anais ... Florianópolis, 2005.

NOGUEIRA, C.A.G.;NOGUEIRA, A.O.; ALMEIDA, S.F.D.C. Preparação para o exame de suficiência: desafios para os docentes do curso de ciências contábeis. In: V Encontro de Práticas Docentes. Anais ... Fortaleza, 2013.

OLIVEIRA NETO, J.D; KUROTORI, I. K. O retorno do exame de suficiência do CFC. Revista de Contabilidade do Mestrado em Ciências Contábeis da UERJ. v.14, n.1, p. 1$18,2009$. 
PINHEIRO, F.M.G.; DIAS FILHO, J.M.; LIMA FILHO, R.N.; LOPES, L.M.S. O perfil do contador e os níveis de habilidades cognitivas nos exames Enade e suficiência do CFC: uma análise sob a perspectiva da taxonomia de Bloom. Revista Contemporânea de Economia e Gestão. V. 11, N.1, jan/jun 2013.

ROTHEN, J.C.; BARREYRO, G.B. Expansão da educação superior no Brasil e avaliação institucional: um estudo do Sistema Nacional de Avaliação da Educação Superior (SINAES) na "Revista Avaliação". Série-Estudos.n” 30, 2010

SANTOS, C.A.; GONÇALVES, M.L.; NUNES, R.S.; PINTO, J.S. Um Estudo da Relação do Exame de Suficiência com a Qualidade do Profissional de Contabilidade: percepção dos docentes do Ensino Superior de Ciências Contábeis de Mato Grosso do Sul. In: XIX Congresso Brasileiro de Contabilidade. Anais ... Belém, 2012

TERRES, J.C. Exame de suficiência da profissão contábil: um estudo envolvendo o posicionamento de contabilistas e estudantes do curso de ciências contábeis a respeito de sua aplicabilidade. In: XI Colóquio Internacional sobre Gestão Universitária na América do Sul. Anais ...Florianópolis, 2011.

VALNIER, T.P. Desempenho dos egressos do curso de ciências contábeis da UNESC formados em 2010/2 e 2011/1 no Exame de Suficiência. Trabalho de Conclusão do curso de Ciências Contábeis. UNESC, Criciuma, 2012.

VERHINE, R.E.; DANTAS, L.M.V.; SOARES, J.F. Do Provão ao ENADE: uma análise comparativa dos exames nacionais utilizados no Ensino Superior Brasileiro. Ensaio: Avaliação das Políticas Públicas da Educação. v.14, n.52, 2006.

UMBACH, P.D. Web surveys: Best practices. New Directions for Institutional Research. v.2004, n.121, 2004. 